\title{
Frailty syndrome and self-care ability in elderly patients with heart failure
}

\author{
This article was published in the following Dove Press journal: \\ Clinical Interventions in Aging \\ 18 May 2015 \\ Number of times this article has been viewed
}

\author{
Izabella Uchmanowicz' \\ Marta Wleklik' \\ Robbert JJ Gobbens ${ }^{2,3}$ \\ 'Department of Clinical Nursing, \\ Wrocław Medical University, Wrocław, \\ Poland; ${ }^{2}$ Faculty of Health, Sports and \\ Social Work, Inholland University \\ of Applied Sciences, Amsterdam, \\ ${ }^{3}$ Zonnehuisgroep Amstelland, \\ Amstelveen, the Netherlands
}

Background: Chronic heart failure is a serious medical condition. Recently, there has been an increasing interest in frailty syndrome and self-care levels among patients with cardiovascular conditions. Demonstrating the influence of frailty syndrome on self-care could improve the quality of self-care and prevent the adverse effects of frailty syndrome. The purpose of this study was to assess the influence of frailty syndrome on the self-care capabilities of patients with chronic heart failure, and to identify factors associated with frailty.

Methods: The data were collected between January and July 2014. The study included 110 patients with chronic heart failure who were hospitalized in the cardiology clinic. Frailty syndrome was assessed using the Tilburg Frailty Indicator, a self-report questionnaire, and selfcare behavior was assessed using the European Heart Failure Self-Care Behavior Scale.

Results: Fifty-four percent of the study patients were male and $46 \%$ were female. The mean age was $66 \pm 11$ years, the mean Tilburg Frailty Indicator score was $7.45 \pm 3.02$ points, and the mean self-care level was $27.6 \pm 7.13$ points. Correlation analyses showed that patients with higher scores in the social components of the frailty scale had better self-care capabilities. Frailty was associated with age, education, duration of heart failure, number of hospitalizations, and New York Heart Association class. The effects of these patient characteristics differed across components of frailty (physical, psychological, social).

Conclusion: The social components of frailty syndrome adversely affect the ability to selfcare in elderly patients with heart failure. It is relevant to use a multidimensional measurement of frailty.

Keywords: frailty syndrome, self-care, heart failure

\section{Introduction}

Heart failure (HF) affects almost $3 \%$ of the general population, with a prevalence of $10 \%-20 \%$ in the elderly. ${ }^{1} \mathrm{HF}$ is an increasingly serious epidemiological and clinical issue, and numbers of patients with the disease are growing due to, among other factors, longer lifespans and higher survival rates of patients with acute coronary syndrome. Despite the many pharmacological treatment options and use of implantable devices, patients with HF are still frequently hospitalized, and the survival rate of patients with normal ejection fraction has not improved (there has been a slight improvement in the survival rates of patients with impaired ejection fraction). According to statistics cited by Jencks et al one in five Medicare patients with HF is rehospitalized within 30 days, and nearly one in three within 90 days from discharge. ${ }^{2}$ Importantly, HF accounted only for $37 \%$ of rehospitalizations. The remaining ones were due to other conditions. The most common diseases resulting in rehospitalizations in patients with $\mathrm{HF}$ are chronic obstructive pulmonary disease, kidney failure, type 2 diabetes mellitus, depression, and lower respiratory tract conditions. ${ }^{3}$ Most patients with HF are elderly,

ie, over 65 years of age. The relationship between HF and frailty syndrome (FS) is of
Correspondence: Izabella Uchmanowicz Department of Clinical Nursing, Wrocław Medical University, ul Bartla 5, 5I-618 Wrocław, Poland

$\mathrm{Tel}+48$ 7। $784 \quad 1824$

Fax +48 7I 3459324

Email izabella.uchmanowicz@umed.wroc.pl 
particular interest, as HF often co-occurs with other diseases and syndromes, including FS. FS is one of the key issues in present-day geriatrics and an exponent of old biological age. Recently, there has been increasing interest in FS among cardiovascular patients. Patients diagnosed with FS are at higher risk of falling, decreased mobility, decreased ability to perform basic activities of daily living, frequent hospitalizations, and death. ${ }^{4}$

The most recent definitions of FS adopt a multi-dimensional view: frailty is defined as a dynamic state affecting an individual who experiences losses in one or more domains of human functioning (physical, psychological, social), which is caused by the influence of a range of variables and which increases the risk of adverse outcomes. ${ }^{5}$ Identifying FS in patients with HF is clinically significant, as the syndrome adversely affects the patients' prognosis.

Furthermore, concurrent FS affects the diagnosis and treatment of HF in the elderly. FS and other comorbidities make diagnosing HF in elderly patients more difficult, as shown by Fuat et al. ${ }^{6}$ This is due to the fact that symptoms such as shortness of breath and fatigue are common among the elderly, and may be unrelated to HF, especially in patients with no diastolic dysfunction of the left ventricle. ${ }^{7}$ Another important issue is the underrepresentation of frail patients in clinical studies. Such patients are not included in studies for a number of reasons. They are less mobile, and thus less capable of attending a clinical center. Because of cognitive impairment they may be unable to provide informed consent. Moreover, they are often excluded because of concurrent multiple organ dysfunction. ${ }^{8}$ The underrepresentation of frail, thus mainly elderly, patients in clinical studies results in insufficient knowledge regarding the effectiveness of various treatments in this group. ${ }^{7}$

\section{Self-care in $\mathrm{HF}$}

Effective self-care is of crucial importance in the management of HF. Self-care is a term comprising a patient's behaviors contributing to maintenance of a stable physiological state. It also involves reacting to any symptoms that may occur and alleviating them. ${ }^{9}$ Self-care is a complex process that involves adherence to medical regimens, interpretation of HF symptoms, and the ability to perform early self-management and cooperate with caregivers. ${ }^{10}$ Some self-management strategies, such as monitoring one's weight and self-adjustment of diuretics, are recommended in the American Heart Association guidelines. ${ }^{11}$ Multiple geriatric conditions associated with cognitive, hearing, and eyesight impairment limit the ability to maintain self-care.
Therefore, identification of frailty in patients with HF may be important from the clinical point of view, as this condition adversely affects the course of the disease; it may also have an impact on self-care capabilities, because frailty contributes to a higher frequency of emergency department visits, hospitalizations, falls, and higher mortality in $\mathrm{HF}$ patients.

\section{Aim of the study}

Considering the increasing age of HF patients, a special approach to their treatment is required, with more attention paid to geriatric conditions, such as poor mobility, multiple disabilities, and cognitive impairment that may affect selfcare capabilities. The purpose of this study was to evaluate the correlation between FS and self-care capabilities, and to assess which factors are associated with frailty.

\section{Materials and methods \\ Participants}

The study was performed in the cardiology clinic in Wrocław, Poland. The data were collected from January, 2014 to July, 2014. It included 110 patients (59 male, 51 female) with a mean age of $66.01 \pm 11.40$ years, diagnosed with chronic HF. Inclusion criteria were as follows: clinically confirmed HF diagnosis, the patient's written informed consent, and age over 60 years. Exclusion criteria were psychiatric disorders, requirement for intensive cardiac care, and previous stroke.

\section{Instruments}

Demographic and sociodemographic data (age, sex, years of education, marital status) were obtained from interviews performed by a cardiac nurse and patient records. Clinical data, such as New York Heart Association (NYHA) functional class, number of rehospitalizations, and duration of the disease were obtained from records and personal interviews performed by a cardiac nurse with the participants.

Frailty was measured using the Polish version of the Tilburg Frailty Indicator (TFI). ${ }^{12}$ The TFI consists of two parts. One addresses sociodemographic characteristics of a participant (sex, age, marital status, country of origin, educational level, monthly income) and other potential determinants of frailty (lifestyle, multimorbidity, life events, home living environment). The second part addresses components of frailty. Part two of the TFI comprises 15 self-reported questions divided into three domains. The physical domain ( $0-8$ points) consists of eight questions related to physical health, unexplained weight loss, difficulty 
in walking, balance, hearing problems, vision problems, strength in hands, and physical tiredness. The psychological domain (0-4 points) comprises four items related to cognition, depressive symptoms, anxiety, and coping. The social domain ( $0-3$ points) comprises three questions related to living alone, social relationships, and social support. Eleven items of part two of the TFI have two response categories ("yes" and "no"), while the remaining items have three ("yes", "no", and "sometimes"). "Yes" or "sometimes" responses are scored 1 point each, while "no" responses are scored 0 . The instrument's total score may range from 0 to 15: the higher the score, the higher the patient's frailty. Frailty is diagnosed when the total TFI score is $\geq 5$. Previous studies suggest that the TFI is a valid and reliable instrument for measuring frailty. ${ }^{5,12-15}$

\section{Self-reported self-care}

Self-reported maintenance behaviors were measured using the European Heart Failure Self-care Behavior Scale (EHFScBS), Polish version. ${ }^{16}$ This questionnaire was based on a theoretical construct of self-care by Orem. ${ }^{17}$ In the present study, we used EHFScBS-9 item, which includes nine questions related to various aspects of self-care, including daily control of weight, level of physical activity, use of a low sodium diet, amount of ingested fluids, self-monitoring, and appropriate reaction to potential symptoms of decompensation. The EHFScBS-9 currently has a score from 9 to 45 , with a higher score indicating worse self-care. A standardized score from 0 to 100 with a higher score indicating better selfcare can make interpretation of the score easier. The instrument has passed validation and psychometric verification in many populations and culture groups, and was the subject of many translations and adaptations. ${ }^{18-22}$ The study was approved by the bioethics committee of Wrocław Medical University (approval KB 521/2014).

\section{Statistical analysis}

The study used a significance level of 0.05 , ie, outcomes were considered to be statistically significant at $P<0.05$. The software used for the analysis was Statistical Package for the Social Sciences for Windows version 17.0 (SPSS Inc, Chicago, IL, USA). Correlations were analyzed using Pearson's $r$, if both scales were measured using a quantitative scale, with variable distributions close to normal. If distributions were not normal, or variables were not ordinal, Spearman's rho was used. To assess whether the analyzed factors were predictors for dependent variables, the stepwise regression method was used.

\section{Results}

The study included 110 patients with HF. Table 1 shows the patients' sociodemographic and clinical data. Fiftyfour percent of the study patients were male and $46 \%$ were female. The mean age was $66 \pm 11$ years. Most patients were married (67\%), while 23\% were widowed. Poland was the birthplace of $89 \%$ of patients, with most of the remaining $11 \%$ born in Ukraine. Sixty-eight percent of the patients were educated to high school level, 17\% had either primary or no education, while $15 \%$ had higher vocational, college, or university education. One in three patients had a monthly income exceeding PLN 2,100, 15\% earned PLN

Table I Patient sociodemographic and clinical data

\begin{tabular}{|c|c|c|}
\hline Characteristic & Number & Percentage \\
\hline \multicolumn{3}{|l|}{ Sex } \\
\hline Female & 51 & 46.36 \\
\hline Male & 59 & 53.64 \\
\hline Age (mean, SD) & 66.01 & $1 \mathrm{I} .40$ \\
\hline \multicolumn{3}{|l|}{ Marital status } \\
\hline Married/living with a partner & 74 & 67.27 \\
\hline Single & 2 & 1.82 \\
\hline Separated/divorced & 9 & 8.18 \\
\hline Widowed & 25 & 22.73 \\
\hline \multicolumn{3}{|l|}{ Country of birth } \\
\hline Poland & 98 & 89.09 \\
\hline Other & 12 & 10.91 \\
\hline \multicolumn{3}{|l|}{ Education } \\
\hline None or primary & 19 & 17.27 \\
\hline High school & 75 & 68.18 \\
\hline Higher vocational/college/university & 16 & 14.55 \\
\hline \multicolumn{3}{|l|}{ Income per month } \\
\hline$\leq$ PLN 600 & 4 & 3.64 \\
\hline PLN 60I-900 & 7 & 6.36 \\
\hline PLN 90I-I,200 & 13 & 11.82 \\
\hline PLN I,20I-I,500 & 17 & 15.45 \\
\hline PLN I,50I-I,800 & 14 & 12.73 \\
\hline PLN I,80I-2, 100 & 17 & 15.45 \\
\hline$\geq$ PLN 2,I0I & 38 & 34.55 \\
\hline \multicolumn{3}{|l|}{ Two or more illnesses or chronic illnesses } \\
\hline Yes & 12 & 10.91 \\
\hline No & 98 & 89.09 \\
\hline Duration of HF in years (mean, SD) & 8.80 & 6.03 \\
\hline $\begin{array}{l}\text { Number of hospitalization, during } \\
\text { the last year (mean, SD) }\end{array}$ & 1.75 & 1.08 \\
\hline \multicolumn{3}{|l|}{ NYHA class } \\
\hline I & 12 & 10.91 \\
\hline II & 58 & 52.73 \\
\hline III & 38 & 34.55 \\
\hline IV & 2 & 1.82 \\
\hline \multicolumn{3}{|l|}{ Comorbidities } \\
\hline No & 98 & 89.09 \\
\hline Yes & 12 & 10.91 \\
\hline
\end{tabular}

Abbreviations: HF, heart failure; NYHA, New York Heart Association Functional Classification; SD, standard deviation; PLN, Polish zloty. 
1,800-2,100 a month, and 15\% earned PLN 1,200-1,500 a month.

The mean duration of HF was $9 \pm 6$ years and the mean number of hospitalizations was $1.75 \pm 1.08$. Most patients were classified as having NYHA class II functional status (53\%), 35\% were classified in NYHA class III, 11\% were in class I, and $2 \%$ were in class IV. Eleven percent of the patients had comorbidities. Table 2 shows the descriptive statistics for the TFI scale.

The patients had a mean physical component score of $4.15 \pm 1.95$ points, their mean psychological component score was $2.13 \pm 1.07$ points, and their mean social component score was $1.18 \pm 0.89$ points. In the study group, the lowest frailty score on the TFI scale was 0 points and the highest was 14 points; the mean TFI score was $7.45 \pm 3.02$ points. Table 3 shows descriptive statistics for the EHFScBS.

In the study group, the lowest self-care level was 11 points and the highest was 40 points; the mean self-care level was $27.6 \pm 7.13$ points; the lowest mean score in the EHFScBS was obtained in question 8 (1.45); and the highest mean score was obtained in question 9 (4.01). Subsequently, correlations between the TFI and EHFScBS were analyzed using Pearson's $r$. Table 3 shows the correlation coefficients from these analyses. Correlation analyses showed that patients with higher scores in the social domain of the TFI had better self-care.
Correlations between TFI score and age, years in education, patient income, duration of illness, number of hospitalizations, and NYHA class were analyzed using Spearman's rho. Table 4 shows the correlation coefficients from these analyses.

The correlation analyses showed that total frailty and each of its components (physical, psychological, social) increased with advancing patient age. The analyses showed also that the total frailty score and the physical components score decreased as the number of years in education increased. The total frailty score, as well as the physical and social component scores, increased with duration of illness. Patients who were hospitalized more frequently had higher scores in the total frailty and social frailty components. The total frailty score, as well as the physical and psychological component scores, increased with NYHA class. Finally, the correlation analyses showed no statistically significant relationship between the total frailty score, its components, and patient income.

\section{Discussion}

Considering the increasing age of HF patients, a special approach to their treatment is required, with more attention paid to geriatric conditions, such as poor mobility, multiple disabilities, and cognitive impairment that may affect selfcare capabilities.

Table 2 Descriptive statistics for the Tilburg Frailty Indicator

\begin{tabular}{|c|c|c|c|}
\hline Part B - Frailty components & Yes, n (\%) & Sometimes, n (\%) & No, n (\%) \\
\hline \multicolumn{4}{|l|}{ BI Physical components } \\
\hline II. Do you feel physically healthy? & $16(14.5)$ & & $94(85.5)$ \\
\hline 12. Have you lost a lot of weight recently without wishing to do so? & $16(14.5)$ & & $94(85.5)$ \\
\hline 13. Do you have difficulty in walking? & $64(58)$ & & $46(42)$ \\
\hline 14. Do you have difficulty maintaining your balance? & $4 \mathrm{I}(37)$ & & $69(63)$ \\
\hline I5. Do you have poor hearing? & $28(25)$ & & $82(75)$ \\
\hline 16. Do you have poor vision? & $53(48)$ & & $57(52)$ \\
\hline 17. Do you have lack of strength in your hands? & $65(59)$ & & $45(4 I)$ \\
\hline 18. Do you have physical tiredness? & $95(86)$ & & $15(14)$ \\
\hline \multicolumn{4}{|l|}{ B2 Psychological components } \\
\hline 19. Do you have problems with your memory? & $16(14.5)$ & $2(2)$ & $36(33)$ \\
\hline 20. Have you felt down during the last month? & $50(45)$ & $2(2)$ & $26(24)$ \\
\hline 21. Have you felt nervous or anxious during the last month? & $28(25)$ & $2(2)$ & $13(12)$ \\
\hline 22. Are you able to cope with problems well? & $73(66)$ & & $37(34)$ \\
\hline \multicolumn{4}{|l|}{ B3 Social components } \\
\hline 23. Do you live alone? & $23(21)$ & & $87(79)$ \\
\hline 24. Do you sometimes miss having people around you? & $46(42)$ & $2(2)$ & $30(27)$ \\
\hline 25. Do you receive enough support from other people? & $83(75.5)$ & & $27(24.5)$ \\
\hline Frailty level of the study patients, mean, SD & $7.45(3.02)$ & $0-14$ & \\
\hline Frailty syndrome & $83(75.5)$ & & $27(24.5)$ \\
\hline Physical component & $4.15(1.95)$ & $0-8$ & \\
\hline Psychological component & $2.13(1.07)$ & $0-4$ & \\
\hline Social component & $1.18(0.89)$ & $0-3$ & \\
\hline
\end{tabular}

Abbreviation: SD, standard deviation. 
Table 3 Descriptive statistics for the European Heart Failure Self-care Behavior Scale

\begin{tabular}{|c|c|c|}
\hline Item number & Mean (SD) & Range \\
\hline I. I weigh myself every day & $3.7 \mathrm{I}(1.44)$ & $\mathrm{I}-5$ \\
\hline $\begin{array}{l}\text { 2. If SOB increases I contact my doctor } \\
\text { or nurse }\end{array}$ & $3.11(1.43)$ & $\mathrm{I}-5$ \\
\hline $\begin{array}{l}\text { 3. If legs/feet are more swollen, I contact } \\
\text { my doctor or nurse }\end{array}$ & $3.13(1.44)$ & $\mathrm{I}-5$ \\
\hline $\begin{array}{l}\text { 4. If I gain weight more than } 2 \mathrm{~kg} \text { in } 7 \text { days } \\
\text { I contact my doctor or nurse }\end{array}$ & $3.88(1.3)$ & $1-5$ \\
\hline 5. I limit the amount of fluids & $2.31(1.32)$ & $1-5$ \\
\hline $\begin{array}{l}\text { 6. If I experience fatigue I contact } \\
\text { my doctor or nurse }\end{array}$ & $3.33(1.32)$ & $1-5$ \\
\hline 7. I eat a low salt diet & $2.74(\mathrm{I} .32)$ & $1-5$ \\
\hline 8. I take my medication as prescribed & $1.45(0.89)$ & $1-5$ \\
\hline 9. I exercise regularly & $4.01(1.17)$ & $\mathrm{I}-5$ \\
\hline 10. Self-care level & $27.65(7.13)$ & $11-40$ \\
\hline
\end{tabular}

Abbreviations: SOB, shortness of breath; SD, standard deviation.

Studies show that $25 \%-50 \%$ of cardiovascular patients suffer from FS. Patients with HF and concurrent FS are at a higher risk of experiencing adverse effects of their disease compared with non-frail patients. ${ }^{23}$ The prevalence of FS is currently approximately $40 \%$, and epidemiological forecasts indicate that it will rise as the population ages. ${ }^{24}$ Frailty occurs more frequently in patients with HF than among the general population, and serves as an independent predictor of visits to the emergency department, hospitalizations, and mortality. ${ }^{25}$

HF patients' self-care capabilities have been examined by many researchers. ${ }^{26-31}$ Patients continue to have a low level of understanding of self-care. Problems with compliance among patients are common, and there is still no explanation why this happens. As far as we known, there are no previous studies on frailty and self-care behaviors among patients with HF. Therefore, the purpose of this study was to assess the relationship between frailty and its domains (physical, psychological, social) and the self-care capabilities of patients with HF, and to assess which factors are associated with frailty.

The most popular diagnostic criteria for FS are those based on the Cardiovascular Health Study (CHS) definition described by Fried et al. ${ }^{4}$ The five described frailty markers are based on a

Table 4 Coefficients of correlation between the Tilburg Frailty Indicator and the European Heart Failure Self-care Behavior Scale

\begin{tabular}{lll}
\hline Variable & Self-care & \\
\cline { 2 - 3 } & Pearson's $\boldsymbol{r}$ & Significance \\
\hline Frailty & 0.15 & 0.122 \\
Physical components & 0.02 & 0.867 \\
Psychological components & 0.17 & 0.070 \\
Social components & $\mathbf{0 . 2 6}$ & $\mathbf{0 . 0 0 6}$ \\
\hline
\end{tabular}

Notes: Values shown in bold are statistically significant. narrow definition of frailty. The CHS scale includes five items: slowness, measured with $5 \mathrm{~m}$ gait speed; weakness, measured by handgrip strength; physical inactivity and exhaustion, both measured by a questionnaire; and unintentional weight loss $>10 \mathrm{lb}$ over one year, measured by self-report. ${ }^{4}$ In our study, we used the multidimensional instrument that is based on the broad definition of frailty which distinguishes three interrelated types of frailty, ie, physical, psychological, and social. ${ }^{5,12,13}$

The present study showed that only higher scores in the social components of the TFI questionnaire were correlated with better self-care capabilities in HF patients. No studies were found that reported on this relationship, so this finding is novel and has not been evaluated or addressed by other studies. Some authors have confirmed the importance of the social component, indicating that HF patients who have no family, live alone, and are at risk of social isolation, are prone to poor self-care and should receive more support in this regard. Social support from family and friends results in better adherence, lower rehospitalization rates, and fewer symptoms of depression in patients with HF. ${ }^{32}$ Self-care capabilities of HF patients, especially with regard to medication, are adversely affected by multimorbidity and polypharmacy. Therefore, the support of family members is of crucial importance in terms of supervising medication and optimizing self-control and self-care in elderly patients with concurrent frailty. ${ }^{33}$

Severe FS is found in the elderly, whose physical and psychosocial functioning deteriorates with age. In the present study, correlations were found between increasing age and increasing frailty (Table 5).

Literature includes the basic characteristics of a prospective cohort study called FRAIL-HF, aiming to perform comprehensive evaluation of elderly patients hospitalized for HF. The authors include numerous factors that may affect the prognosis of HF patients, but consider FS, cognitive dysfunction, social support, and self-care capabilities to be of special clinical and functional importance. In the FRAIL-HF study, frailty was found in $70.2 \%$ of patients, while self-care capabilities were scored using the EHFScBS questionnaire at $29.35 \pm 5.5$ points. ${ }^{34}$ By means of comparison, in our study, frailty was found in $75 \%$ of patients and self-care capabilities were scored at $27.65 \pm 7.13$.

The present study shows that hospitalized patients were more likely to have higher frailty scores. Both Gobbens and van Assen and Daniels et al considered FS to be an indicator of disability, and also of increased use of medical care and hospitalization, which may be a consequence of impaired self-care capabilities in elderly patients with chronic HF. ${ }^{35,36}$ 
Table 5 Coefficients of correlation between the Tilburg Frailty Indicator and sociodemographic and clinical characteristics

\begin{tabular}{|c|c|c|c|c|}
\hline Variable & Frailty & $\begin{array}{l}\text { Physical } \\
\text { component }\end{array}$ & $\begin{array}{l}\text { Psychological } \\
\text { component }\end{array}$ & $\begin{array}{l}\text { Social } \\
\text { component }\end{array}$ \\
\hline \multicolumn{5}{|l|}{ Age } \\
\hline Spearman's rho & 0.46 & 0.52 & 0.21 & 0.25 \\
\hline Significance & 0.000 & 0.000 & 0.031 & 0.009 \\
\hline \multicolumn{5}{|l|}{ Education in years } \\
\hline Spearman's rho & -0.21 & -0.22 & -0.17 & -0.05 \\
\hline Significance & 0.025 & 0.020 & 0.082 & 0.577 \\
\hline \multicolumn{5}{|l|}{ Income } \\
\hline Spearman's rho & 0.03 & -0.05 & 0.08 & 0.10 \\
\hline Significance & 0.763 & 0.571 & 0.392 & 0.320 \\
\hline \multicolumn{5}{|c|}{ Duration of HF in years } \\
\hline Spearman's rho & 0.37 & 0.39 & 0.18 & 0.28 \\
\hline Significance & 0.000 & 0.000 & 0.062 & 0.003 \\
\hline \multicolumn{5}{|l|}{ Hospitalizations (n) } \\
\hline Spearman's rho & 0.20 & 0.12 & 0.16 & 0.19 \\
\hline Significance & 0.034 & 0.218 & 0.091 & $0.04 I$ \\
\hline \multicolumn{5}{|l|}{ NYHA class } \\
\hline Spearman's rho & 0.37 & 0.31 & 0.38 & 0.06 \\
\hline Significance & 0.000 & 0.001 & 0.000 & 0.507 \\
\hline
\end{tabular}

Notes: Values shown in bold are statistically significant.

Abbreviations: HF, heart failure; NYHA, New York Heart Association functional class.

The relationship between HF and FS is a complex one. Additionally, both HF and FS can adversely affect the course of concurrent diseases, and increase the risk of falling, disability, hospitalization, and death. ${ }^{37}$ As regards this study, it should be emphasized that a longer duration of HF was correlated with increased frailty. Further, higher NYHA classes, reflecting the clinical severity of $\mathrm{HF}$, were correlated with increased frailty among the study patients. Tjam et al showed that FS is a better predictor of mortality than NYHA class. ${ }^{38}$

It is worth noting that only the social frailty components were associated with the ability to self-care in patients with $\mathrm{HF}$, and in addition, that the effect of sociodemographic and clinical characteristics of patients with HF on frailty differs across the components of frailty (physical, psychological, social). This finding emphasizes the importance of a multidimensional assessment of frailty.

In the case of elderly patients with moderate and severe $\mathrm{HF}$, interventions from a multidisciplinary team, including family members, should focus on intensive support in selfcare and self-control. ${ }^{39}$ Such actions will allow for optimizing the patient's clinical condition and their physical and psychosocial functioning, and thereby maintaining or improving their quality of life.

\section{Limitations of the study}

The results of the present study should be interpreted in the context of potential limitations. First, it did not investigate the effect of other factors, eg, levels of cognition and knowledge that could potentially affect the ability of elderly patients with HF to self-care. Future research could analyze the predictive value of these factors in relation to self-care and FS. Second, one cannot guarantee that the selection of our participants was completely random.

\section{Disclosure}

The authors report no conflicts of interest in this work.

\section{References}

1. McMurray JJ, Adamopoulos S, Anker SD, et al. ESC guidelines for the diagnosis and treatment of acute and chronic heart failure 2012: The Task Force for the Diagnosis and Treatment of Acute and Chronic Heart Failure 2012 of The European Society of Cardiology. Developed in collaboration with Heart Failure Association (HFA) of the ESC. Eur Heart J. 2012;33:1787-1847.

2. Jencks SF, Williams MV, Coleman EA. Rehospitalizations among patients in the Medicare fee-for-service program. NEngl JMed. 2009;360: $1418-1428$.

3. Braunstein JB, Anderson GF, Gerstenblith G, et al. Noncardiac comorbidity increases preventable hospitalizations and mortality among Medicare beneficiaries with chronic heart failure. J Am Coll Cardiol. 2003; 42:1226-1233.

4. Fried LP, Tangen CM, Walston J, et al. Frailty in older adults: evidence for a phenotype. J Gerontol Biol Sci Med Sci. 2001;56:146-156.

5. Gobbens RJ, van Assen MA, Luijkx KG, Wijnen-Sponselee MT, Schols JM. Determinants of frailty. J Am Med Dir Assoc. 2010;11:356-364.

6. Fuat A, Hungin AP, Murphy JJ. Barriers to accurate diagnosis and effective management of heart failure in primary care: qualitative study. $B M J$. 2003;326:196.

7. Murad K, Kitzman MD. Frailty and multiple comorbidities in the elderly patient with heart failure: implications for management. Heart Fail Rev. 2012;17:581-588.

8. Ridda I, Lindley R, MacIntyre RC. The challenges of clinical trials in the exclusion zone: the case of the trial elderly. Australias J Ageing. 2008; 27:61-66. 
9. Riegel B, Lee SC, Dickson VV, Carlson B. An update on the self-care of heart failure index. J Cardiovasc Nurs. 2009;24:485-497.

10. Clark AM, Freydberg CN, McAlister FA, Tsuyuki RT, Armstrong PW, Strain LA. Patient and informal caregivers' knowledge of heart failure necessary but insufficient for effective self-care. Eur J Heart Fail. 2009; 1:617-621.

11. Yancy CW, Jessup M, Bozkurt B, et al. 2013 ACCF/AHA Guideline for the management of heart failure. A report of the American College of Cardiology American Foundation/American Heart Association Task Force on Practice Guidelines. J Am Coll Cardiol. 2013;62: 147-239.

12. Uchmanowicz I, Jankowska-Polańska B, Łoboz-Rudnicka M, Manulik S, Łoboz-Grudzień K, Gobbens RJ. Cross-cultural adaptation and reliability testing of the Tilburg Frailty Indicator for optimizing care of Polish patients with frailty syndrome. Clin Interv Aging. 2014;9: 997-1001.

13. Gobbens RJ, van Assen MA, Luijkx KG, Schols JM. The predictive validity of the Tilburg Frailty Indicator: disability, health care utilization, and quality of life in a population at risk. Gerontologist. 2012; 52:619-631.

14. Coelho T, Silva C, Santos R, Paúl C, Gobbens RJ, Fernandes L. Portuguese version of the Tilburg Frailty Indicator (TFI): transcultural adaptation and psychometric validation. Geriatr Gerontol Int. September 26, 2014. [Epub ahead of print].

15. Andreasen J, Sørensen EE, Gobbens RJ, Lund H, Aadahl M. Danish version of the Tilburg Frailty Indicator - translation, cross-cultural adaptation and validity pretest by cognitive interviewing. Arch Gerontol Geriatr. 2014;59:32-38.

16. Uchmanowicz I, Łoboz-Rudnicka M, Jaarsma T, Łoboz-Grudzień K. Cross-cultural adaptation and reliability testing of Polish adaptation of the European Heart Failure Self-care Behaviour Scale (EHFScBS). Patient Prefer Adherence. 2014;8:1521-1526.

17. Orem DE. Nursing: Concept of Practice. 5 th ed. St Louis, MO, USA: Mosby; 1995.

18. Jaarsma T, Arestedt KF, Martensson J, et al. The European Heart Failure Self-care Behaviour scale revised into a nine-item scale (EHFScB-9): a reliable and valid international instrument. Eur J Heart Fail. 2009;11:99-105.

19. Jaarsma T, Stromberg A, Ben Gal T, et al. Comparison of self-care behaviours of heart failure patients in 15 countries worldwide. Patient Educ Couns. 2013;92:114-120.

20. Lambrinou E, Kalogirou F, Lamnisos D. The Greek version of the 9-item European heart failure self-care behaviour scale: a multidimensional or uni-dimensional scale? Heart Lung. 2014;43:494-499.

21. Lee KS, Gelow JM, Mudd JO, et al. Validity and reliability of the European Heart Failure Self-care Behaviour Scale among adults from the United States with symptomatic heart failure. Eur J Cardiovasc Nurs. 2013;12:214-218.

22. Köberich S, Glattacker M, Jaarsma T, Lohrmann C, Dassen T. Validity and reliability of the German version of the 9-item European Heart Failure Self-Care Behavior scale. Eur J Cardiovasc Nurs. 2013;12:150-158.
23. Afilalo J. Frailty in patients with cardiovascular disease: why, when and how to measure. Curr Cardiovasc Risk Rep. 2011;5:467-472.

24. Cramm MJ, Twisk J, Nieboer PA. Self-management abilities and frailty are important for healthy aging among community-dwelling older people: a cross-sectional study. BMC Geriatr. 2014;6:28.

25. McNallan SM, Chamberlain AM, Gerber Y, et al. Measuring frailty in heart failure: a community perspective. Am Heart J. 2013;166: 768-774.

26. Artinian NT, Magnan M, Sloan M, Lange MP. Self-care behaviours among patients with heart failure. Heart Lung. 2002;31:161-172.

27. Bennett SJ, Cordes DK, Westmoreland G, Castro R, Donnelly E. Selfcare strategies for symptom management in patients with chronic heart failure. Nurs Res. 2000;49:139-145.

28. Carlson B, Riegel B, Moser DK. Self-care abilities of patients with heart failure. Heart Lung. 2001;30:351-359.

29. Gary R. Self-care practices in women with diastolic heart failure. Heart Lung. 2006;35:9-19.

30. Riegel B, Vaughan Dickson V, Goldberg LR, Deatrick JA. Factors associated with the development of expertise in heart failure self-care. Nurs Res. 2007;56:235-243.

31. Rockwell JM, Riegel B. Predictors of self-care in persons with heart failure. Heart Lung. 2001;30:18-25.

32. Dunbar BS, Clark PC, Quinn C, Gary RA, Kaslow NJ. Family influences on heart failure self-care and outcomes. J Cardiovasc Nurs. 2008; 23:258-265.

33. Marek KD, Stetzer F, Ryan PA, et al. Nurse care coordination and technology effects on health status of frail older adults via enhanced self-management of medication: randomized clinical trial to test efficacy. Nurs Res. 2013;62:269-278.

34. Vidan TM, Sanchez E, Fernandez-Aviles F, et al. FRAIL-HF, a study to evaluate the clinical complexity of heart failure in nondependent older patients: rationale, methods and baseline characteristics. Clin Cardiol. 2014;37:725-732.

35. Gobbens RJ, van Assen MA. Frailty and its prediction of disability and health care utilization: the added value of interviews and physical measures following a self-report questionnaire. Arch Gerontol Geriatr. 2012;12:369-379.

36. Daniels R, van Rossum E, Beurskens A, van den Heuvel W, de Witte L. The predictive validity of three self-report screening instruments for identifying frail older people in the community. BMC Public Health. 2012;12:69.

37. Samala VR, Navas V, Saluke E, Ciocon OJ. Heart failure in frail, older patients: we can do more. Cleve Clin J Med. 2011;12:837-845.

38. Tjam EY, Heckman GA, Smith S, et al. Predicting heart failure mortality in frail seniors: comparing the NYHA functional classification with the Resident Assessment Instrument (RAI). Int J Cardiol. 2012; 155:75-80.

39. Gilmour J, Strong A, Chan H, Hanna S, Huntington A. Primary health care nurses and heart failure education: a survey. J Prim Health Care. 2014;6:229-237.
Clinical Interventions in Aging

\section{Publish your work in this journal}

Clinical Interventions in Aging is an international, peer-reviewed journal focusing on evidence-based reports on the value or lack thereof of treatments intended to prevent or delay the onset of maladaptive correlates of aging in human beings. This journal is indexed on PubMed Central, MedLine,

\section{Dovepress}

CAS, Scopus and the Elsevier Bibliographic databases. The manuscript management system is completely online and includes a very quick and fair peer-review system, which is all easy to use. Visit http://www.dovepress. com/testimonials.php to read real quotes from published authors. 